\title{
Children with Juvenile Rheumatoid Arthritis at School
}

\section{Functional Problems, Participation in Physical Education}

\author{
The Implementation of Public Law 94-142
}

Rosanne Whitehouse, MPH, Jean T. Shope, PhD, Donita B. Sullivan, MD, Chen-Lin Kulik, PhD

\begin{abstract}
Parents of 135 children with juvenile rheumatoid arthritis (JRA) completed a mailed questionnaire about problems at school. Writing was the most frequently reported difficulty, with hand involvement causing more problems than decreased mobility. Compared to children with pauciarticular JRA, those with polyarticular or systemic JRA were significantly more likely to miss school, experience problems, participate less in physical education, have an Individualized Educational Plan (IEP) developed, and receive related services.

Only 39 parents had heard of PL 94-142, and only 21 of those could define the federal law. Twenty children had an IEP within the previous two years. Possible deficiencies in the implementation of PL 94-142 were discovered.

This study demonstrates that the treatment of children with JRA should include efforts to: 1 ) identify and remediate potential performance limitations before they become problematic at school; 2) communicate this information to parents and school personnel; 3) and improve parents' awareness and understanding of $P L$ 94-142.
\end{abstract}

HILDREN WITH JUVENILE RHEUMATOID ARTHRITIS (JRA) are expected to develop academically and socially despite experiencing a chronic, disabling, and uncomfortable condition. Although these children may have the ability to func-

From the Departments of Pediatrics and Communicable Diseases, Postgraduate Medicine and Health Professions Education, and the Center for Research on Learning and Teaching, The University of Michigan, Ann Arbor, Michigan.

Funded in part by grant \#NIH-NIAMDD AM20557 to The University of Michigan Multipurpose Arthritis Center.

Correspondence to: Jean T. Shope, PhD, Assistant Professor, Department of Postgraduate Medicine and Health Professions Education, G1215 Towsley Center, The University of Michigan Medical School, Ann Arbor, Michigan 48109-0201.

Received for publication August 1988, revised May 1989, and accepted June 1989. tion as well as their peers in many areas, in others their abilities are compromised by their disease. The effects of JRA may impact on many activities throughout a child's school day.

For health care providers treating children with JRA, reports of problems at school are common and require frequent communication with the school. Stoff ${ }^{\mathrm{l}}$ conducted a needs assessment of 64 school age children with rheumatic diseases, 37 of which were children diagnosed with JRA. The assessment highlighted: poor attendance; difficulty with climbing stairs, waiting in line, handwriting, and participating in physical education; infrequent support services; poor understanding by teachers and peers of arthritis in children; and concern by parents about social issues. 
The majority of children with JRA are able to attend regular schools. However, for some, the physical effects of arthritis make it difficult to participate fully in classroom and school-related activities. PL 94-142, the Education for All Handicapped Children Act passed by congress in 1975, provides for "related services" such as occupational and physical therapy and mandates adapted physical education; but only for children who need "special" classroom education. Because children with JRA infrequently require special education, the implementation of $\mathrm{PL}$ 94-142 has been inconsistent. ${ }^{2}$ Classroom teachers may have inadequate training or experience in working with handicapped children or feel that a handicapped child requires too much time and energy. Integration of the handicapped child, for example, into physical education activities is difficult. Physical education teachers may lack adequate knowledge to determine which activities are appropriate for a handicapped child. ${ }^{3}$

The University of Michigan Pediatric Rheumatology Clinic (UMPRC), with an active population of over 200 children with JRA, conducted a study to obtain specific information from parents about school problems that children with JRA were experiencing. Data were sought regarding: school attendance; ADL problems; physical education participation; knowledge of PL 94-142 and its implementation; and availability and use of related services.

\section{Methods}

A self-administered questionnaire was developed, pretested, and revised as necessary. The questionnaire was sent with a return-addressed, postage-paid envelope to the 188 UMPRC families with schoolaged children, who had received outpatient care during a one year period. Nonrespondents were reminded by postcard after 3 weeks, and by telephone 2 weeks later. Of the 188 families surveyed, 81 percent (152) returned completed questionnaires. Seventeen questionnaires from families whose children were not yet attending school or whose children had graduated from high school were excluded from the analyses, leaving 135 usable questionnaires.

The precoded questionnaire contained 67 items, the majority of which required parents to select a categorical response, with the remainder requiring scaled or narrative responses. Narrative responses were coded by grouping similar responses into identifiable categories. To determine parent knowledge about PL 94-142, parents were asked what PL 94-142 meant for their child. They were considered to have knowledge of the law if their answer included at least one of four key points: equal opportunity to learn; access to help; education in the least restrictive environment; and a right to as full participation as possible.

Medical records and physician's reports were used to classify children by arthritis type (systemic, polyarticular, and pauciarticular), as described by Brewer $e t$ $a l .{ }^{4,5}$ When arthritis type group sizes were large enough, differences between the three types were analyzed. For some analyses, the systemic and polyarticular types were combined.

Data analysis methods included: chi-square, analysis of variance, correlation, regression, and $t$-tests. In cases where expected cell sizes were less than five, Fisher's Exact Probability ${ }^{6}$ was reported. Hierarchical Cluster Analysis ${ }^{7}$ was used to determine which individual ADL problems clustered together into ADL activity categories.

\section{Results}

\section{Demographic Data}

The study population was 68 percent (92) girls and 32 percent (43) boys with ages ranging from 4 to 18 $($ mean $=11.5)$ years. Grade level distribution of the respondents was: preschool 5 percent, elementary 39 percent, junior high 24 percent, senior high 19 percent, and "unclassified" 1 percent. Eighty-six percent of the parents were married. Employment, either full or parttime, was reported by 96 percent of the fathers and 52 percent of the mothers. Some college education or other training beyond high school was reported by 66 percent of the fathers and 60 percent of the mothers. An annual income of at least $\$ 20,000$ was earned by 73 percent of the families.

The type of arthritis diagnosed in the study population respondent and nonrespondent groups at the time of the study is shown in Table 1. Chi-square analysis revealed no significant differences in the distributions of these two groups $(p<0.05)$, nor were there any significant differences between respondent and nonrespondent groups on age or sex.

\section{School Attendance}

With few exceptions, these 135 children were able to attend their regular public or private school. Only 
TABLE 1. Distribution of Arthritis Type by Respondents and Non-respondents

\begin{tabular}{lcc}
\hline & $\begin{array}{c}\text { Respondents } \\
(\mathrm{n}=135)\end{array}$ & $\begin{array}{c}\text { Non-respondents } \\
(\mathrm{n}=36)\end{array}$ \\
\hline Systemic & $8 \%(11)$ & $19 \%(7)$ \\
Polyarticular & $39 \%(52)$ & $42 \%(15)$ \\
Pauciarticular & $53 \%(72)$ & $39 \%(14)$ \\
\hline
\end{tabular}

Chi-square not significant.

six children were in an alternative school because of JRA and/or the need for special services not available through the regular school.

Arthritis-related school absences occurred for 31 percent (42) of the children. The average was 3.6 days per year and the range was from 1 to 45 days. Children with systemic JRA were more likely to miss school $\left(\chi^{2}=10.6, p<0.05\right)$, averaging 8.6 days per year, than children with polyarticular disease (averaging 2.6 days) or children with pauciarticular disease (averaging 1.6 days).

\section{Parent-School Interaction}

Ninety-three percent of the parents had informed the school about their child's diagnosis of arthritis. In addition, 70 percent of the parents indicated that they had met with the teacher and/or principal to discuss their child's disease and special needs.

\section{ADL Problems at School}

Eleven ADL activities commonly performed in the school setting were listed on the questionnaire as well as an "other problem" category. Parents indicated if their child currently, or in the past, had experienced problems with each of these ADL activities. A total of 177 problems (Table 2) were reported for 63 children. The number of problems per child ranged from 0 to 10 with a mean of 1.4 problems. Of the 63 children who experienced problems, 18 children had one problem, 17 had two, and 28 had three or more problems. Writing represented the most frequent single ADL problem. Dimensional analysis ${ }^{7}$ demonstrated clustering of ADL problems into four categories: hand activities, mobility activities, upper-extremity activities, and blackboard activities. Hand activities were the most frequently reported ADL problems (81), followed by: mobility activities (61); upper extremity activities (29); and blackboard activities (6).
Analysis of variance reveals that children with systemic and polyarticular arthritis experienced more problems overall than children with pauciarticular arthritis $(\mathrm{F}=10.80, \mathrm{p}<0.01)$. They were more likely to experience three or more problems $\left(\chi^{2}\right.$ $=13.3, p<0.01)$ and experienced a greater number of problems with: hand activities $\left(\chi^{2}=10.8, \mathrm{p}<.01\right)$, mobility activities $\left(\chi^{2}=12.65, \mathrm{p}<0.01\right)$, and upper extremity activities $\left(\chi^{2}=5.16, p<0.05\right)$. Older children had more ADL problems than younger children $(r=0.21, p<0.05)$, and children for whom an Individualized Educational Plan (IEP) had been developed had more problems than children for whom an IEP had not been developed $\left(\chi^{2}=4.33\right.$, $\mathrm{P}$ $<0.01)$. Further, the intercorrelations between age, arthritis type, and IEP development were significant. Multiple regression analysis showed that each of these variables contributed significantly to predicting the number of ADL problems $(\mathrm{F}=6.98, \mathrm{p}<0.001)$. Number of ADL problems was also correlated with the reporting of school absences $(\mathrm{r}=0.32, \mathrm{p}<0.01)$.

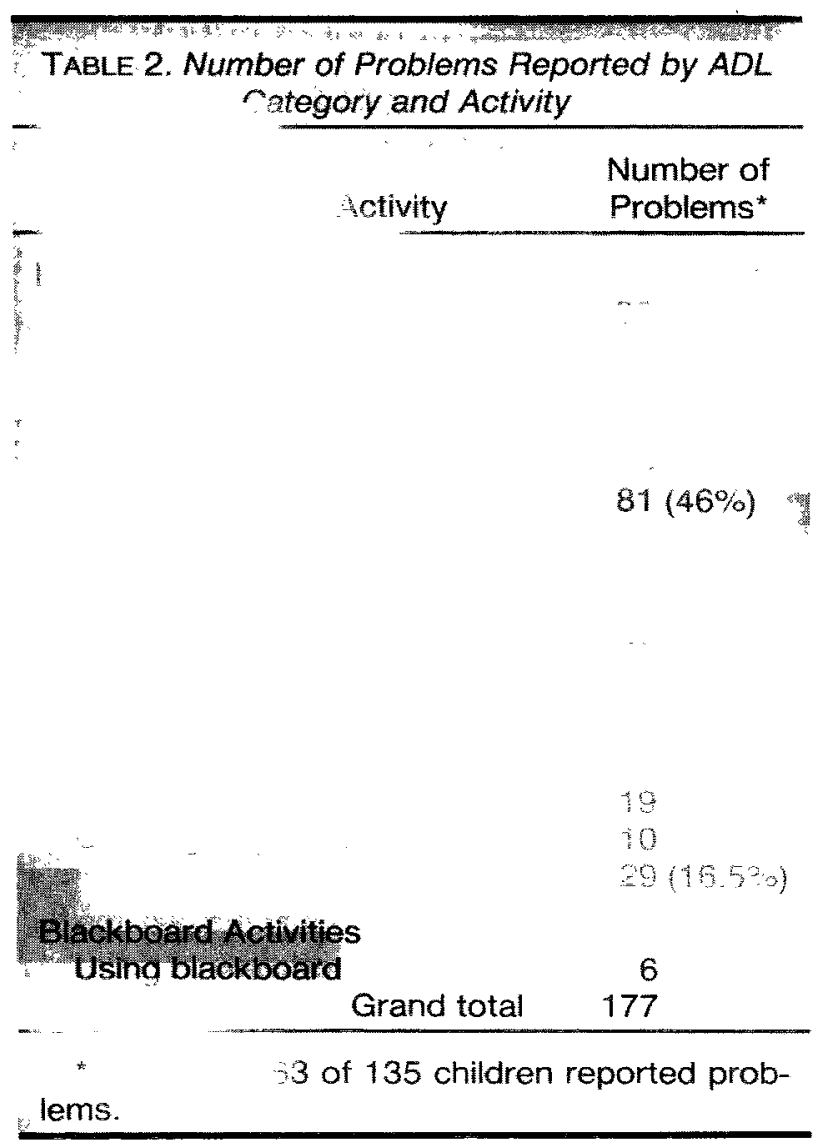




\section{Physical Education Activities}

Ninety-six percent (129) of the children were enrolled in schools that had a physical education program. Fifty-two percent (67) of these children attended physical education and participated fully, 21 percent (27) attended but did not participate fully, 8 percent (10) attended only irregularly and 19 percent (25) did not attend at all. Older children were less likely to participate fully $(\mathrm{r}=0.42, \mathrm{p}<0.01)$, as were children with systemic/polyarticular JRA (F $=11.14, p<0.01)$, and children for whom an IEP had been developed $(\mathrm{t}=2.95, \mathrm{p}<0.01)$. Multiple regression analysis demonstrated that each of these variables made a significant contribution to predicting the degree of participation in physical education activities $(\mathrm{F}=16.734, \mathrm{p}<0.0001)$.

\section{Public Law 94-142}

Parent knowledge of PL 94-142 was assessed by asking parents if they had heard of the law, where they learned about it, and what it meant for their child. Twenty-nine percent (39) of the 135 parents reported having heard of PL 94-142. The sources for parents learning about the law are listed in Table 3. Twenty-one of the 39 parents who had heard about the law were able to give a correct phrase or sentence describing the meaning of the law. Parent knowledge of the law correlated positively and significantly with: mother's educational level $(r=0.37, p$ $<0.01)$, father's educational level $(r=0.23, \mathrm{p}$ $<0.01)$, and family income $(\mathrm{r}=0.22, \mathrm{p}<0.01)$. There was no relationship between knowledge of the law and type of arthritis. Among all parents, 75 percent (101) wanted to learn more about the law.

The implementation of PL 94-142 for this group of children was evaluated by examining the number of children who had an IEP developed as required, and by the implementation of specific provisions of

TABLE 3. Number of Parents Reporting Each Information Source for $P L$ 94-142

\begin{tabular}{lc}
\hline \multicolumn{1}{c}{ Source } & $\begin{array}{c}\text { Number of } \\
\text { Parents }\end{array}$ \\
\hline Written materials & 11 \\
Medical care provider & 5 \\
Child's school & 5 \\
Work/professional background & 5 \\
Involvement with parent group & 4 \\
Course work while attending school & 3 \\
Friend/relative & 2 \\
Other & 4 \\
\hline
\end{tabular}

the law. According to parents' reports, an IEP had been developed for 20 children $(15 \%$ of the study population). The average age of these children was 12 years, with a range from 5 to 17 years. IEP's had been initiated by: the school (11), parents (7), both the parent and school (1), with one case of unknown initiation.

The development of an IEP was significantly related to several variables. Fifteen of the 20 IEPs were developed for children with more severe arthritis (systemic/polyarticular group, $\chi^{2}=9.27, \mathrm{p}<0.01$ ). Parents who had heard of the law were more likely to have participated in an IEP $(r=19, p<0.01)$, but not necessarily be able to correctly define the law. Children for whom IEPs had been developed received more services than those children without IEPs $(t=7.53, \mathrm{p}<0.01)$. Children whose parents had participated in an IEP had more problems than children whose parents had not participated in an IEP $(r=4.33, p<0.01)$. Children with IEP's averaged 1.7 problems each, while children without IEPs averaged 0.7 problems. No IEP had been developed, however, for twenty-two other children with systemic/polyarticular JRA who had three or more ADL problems.

Information concerning the implementation of specific provisions of the law revealed some possible violations. PL 94-142 requires participation of the child's teacher in the development of an IEP. According to parents' reports, eight of the 20 IEP's were conducted without a teacher present. Participation in physical education is mandated by PL 94-142 for all children requiring special education services, either through the regular physical education program with modification of activities if necessary, or through an adapted physical education program. In this study, seven of the 20 IEP children were not participating in any type of physical education, regular or adapted.

\section{Related Services}

Ten related or special services available through school systems for children with special needs are listed in Table 4, along with the number of children reported to be receiving each service. The number of services received per child ranged from zero to eight with a mean of 1.0 service. Thirty-six children received one service, 13 received two, seven received three, and nine received four services.

Children with systemic/polyarticular JRA received significantly more services than children in 
TABLE 4. Number of Children Receiving Related or Special Services

\begin{tabular}{lc}
\hline \multicolumn{1}{c}{ Related Service } & $\begin{array}{c}\text { Number of Children } \\
\text { Receiving }\end{array}$ \\
\hline School counselor & 34 \\
Classroom aide & 22 \\
Older student & 21 \\
Parent volunteer & 17 \\
Physical therapist* & 13 \\
Teacher consultant* & 9 \\
Occupational therapist* & 6 \\
Special transportation* & 6 \\
School psychologist* & 3 \\
School social worker* & 3 \\
\hline
\end{tabular}

* Services significantly associated with an IE.P (Fisher's $p<0.01$ )

the pauciarticular group $(\mathrm{F}=5.79, \mathrm{p}<0.01)$. Children for whom an IEP was done received more services than those for whom an IEP was not done ( $t$ $=7.53, \mathrm{p}<0.01$ ). Multiple regression analysis revealed that each variable contributed significantly to predicting the number of services received ( $F$ $=31.254, \mathrm{p}<0.0001)$. IEP development was significantly associated with receiving the services of a: teacher consultant (Fisher's $\mathrm{p}<0.01$ ); occupational therapist (Fisher's $\mathrm{p}<0.01$ ); physical therapist (Fisher's $p<0.01$ ); school psychologist (Fisher's $p$ $<0.01$ ); and special transportation (Fisher's $\mathrm{p}<$ 0.01 ).

\section{Discussion}

The school experience contributes significantly to every child's academic, social, and emotional development. Children with JRA should have every opportunity to benefit from these developmental experiences. Insight and direction are provided by the identification of several important issues through the data collected in this study.

The representativeness of this study population, however, is difficult to determine. Other reports of arthritis types are based upon disease onset, but offer the percentage of systemic arthritis at 10-30 percent, polyarticular arthritis 25-50 percent, and pauciarticular arthritis at $36-45$ percent. ${ }^{8-11}$ The percentages of each arthritis type in this study were determined at the time the questionnaires were distributed when the diagnostic type of some children may have progressed from pauciarticular to polyarticular or from systemic to polyarticular disease. It is also possible that there are differences in treatment methodologies between clinics that could account for differences in severity of disease and the ability of children to perform daily activities. In spite of this study's limitations (no control group, no objective measures of school performance or physical impairment), the results demonstrate that children with JRA experience common, recognizable problems at school that could be effectively addressed through education and intervention programs aimed at preventing or minimizing these problems.

Parents were asked to report only arthritis-related absences instead of total days missed from school. While some authors think parents tend to underreport absences, ${ }^{12}$ Weitzman suggests that parent reporting is probably adequate. ${ }^{13}$ Children in this study with systemic JRA missed more school because of their arthritis than children with polyarticular or pauciarticular disease.

The most unexpected finding was the frequency of problems involving hand activities, with writing problems occurring more than any other problem. The Stoff ${ }^{1}$ study, including 37 children with JRA reported a higher incidence, by parent report, of mobility problems, with handwriting being the most frequent fine motor problem. Taylor ${ }^{14}$ found that parents and teachers rated ADL problems most important, while children with JRA rated problems associated with self-concept and peer relationships higher.

The limited participation in physical education by the children in this study points out the difficulties for the children, parents, and teachers in adequately integrating a child with JRA into a regular physical education program. The difficulty physical education teachers have setting appropriate activity expectations for a handicapped child may be related to a problem documented in a study by Bird, ${ }^{15}$ of 912 physical education teachers. He found that physical education teachers were less knowledgeable about "motor needs and tolerances" than "nature and causes" of disease, especially in regard to orthopedic conditions. Hillman, ${ }^{16}$ reported that ". . . the percentage of handicapped children not served by adapted physical education remains high-perhaps $75 \%$ or more" and suggested that this problem may be due in part to the ". . . unwillingness of parents to probe for adequate comprehensive education services for their children".

Weitzman ${ }^{13}$ suggests that parents may be reluctant to collaborate with school personnel because of "previous painful experiences." Without accurate information, however, school personnel are forced to make their own interpretations, which are often incorrect and can lead to unrealistic and damaging 
management approaches. Whitehouse and colleagues ${ }^{18}$ found that school personnel do not always consider the parent to be very knowledgeable. Yoshida ${ }^{19}$ found that school personnel expected parents to "provide information" but not to "actively participate" in decision making about their child's program. Lusthaus ${ }^{20}$ found that parents felt more comfortable functioning as providers of information than as active participants in decision making.

Only those children in this study who had an IEP received related or special services (occupational therapy, physical therapy, special transportation), which is consistent with the law. (In Michigan, PL 94-142 is more comprehensive than the state mandatory Special Education Act, so PL 94-142 takes precedence.) There were, however, several other children with similar problems who received no services. This relationship between IEP's and services received was found in the total group as well as within arthritis type suggesting that it is the need for or availability of special services (rather than type or number of ADL problems) that stimulates the development of the IEP. Many of these related services are located and offered only at special school sites and therefore parents often choose to give up the services in order to keep their child in a regular school. $^{21}$

For a child with arthritis attending a regular school, the deficiencies in the implementation of PL 94-142 cited in this study do little to support its value. As Baird and Ashcroft suggest, "the related services portion [of PL 94-142 should] be shaped into a new statute requiring that all students be provided related services necessary for them to benefit from education."22 The problems encountered by children with arthritis could be more effectively addressed if health care providers utilized the following proactive, planning approaches in order to make school a positive developmental experience:

- Identify and remediate problems before they occur at school;

- Educate, train and assist parents in communicating, advocating, and participating in decision-making for their children at school;

- Provide information and assistance to school personnel that will enable them to make appropriate decisions for children without having to implement PL 94-142.

\section{Acknowledgment}

The authors wish to express gratitude to the parents who provided the information for this study. Additionally, thanks goes to
Robin Graham-Tomasi for her assistance with coding and data analysis.

\section{References}

1. Stoff E, Molock SD, White PH. A needs assessment of children with rheumatic diseases. J Sch Health 1987;57:162-4.

2. Petovello LR, Sullivan NL. Special Education: An Advocates Manual. Michigan Protection and Advocacy Service for Developmentally Disabled Citizens 1981;14.

3. Weiss R, Karper WB. Teaching the handicapped child in the regular physical education class. J Phys Educ Rehab 1980;32-5,77-8.

4. Brewer E, Bass JC, Baum J, et al. Current proposed revision of JRA criteria. Arthritis Rheum 1977;20:195-9.

5. Fink CW. Clinical, genetic, and therapeutic aspects of Juvenile Arthritis. Clin Rheum Pract 1983;1:100-15.

6. Blalock Jr HM. Fishers exact test. Social Statistics. New York: McGraw-Hill, 1979,292-7.

7. Kulik JA, Revelle WR, Kulik CL. C scale construction by hierarchical cluster analysis. Ann Arbor, MI. Center for Research on Learning and Teaching, University of Michigan, 1972.

8. Cassidy JT. Textbook of Pediatric Rheumatology. New York: John Wiley \& Sons, 1982,179.

9. Schaller JG. Juvenile Rheumatoid Arthritis. Pediatr Ann 1982;11:375-382.

10. Brewer EJ, Giannini EH, Person DA. Juvenile Rheumatoid Arthritis. Philadelphia: WB Saunders, 1982;327-335.

11. Sullivan DB, Cassidy JT, Petty RE. Pathogenic implications of age of onset in juvenile rheumatoid arthritis. Arthr \& Rheum 1975;18:251-5.

12. Cook BA, Schaller K, Krischer JP. School absence among children with chronic illness. J Sch Health 1985;55:265-7.

13. Weitzman M. School absence rates as outcome measures in studies of children with chronic illness. J Chronic Dis 1986;39(10):799-808.

14. Taylor J, Passo MH, Champion VL. School problems and teacher responsibilities in juvenile rheumatoid arthritis. J Sch Health 1987;57:186-90.

15. Bird PJ, Gansneder BM. Preparation of physical education teachers as required under Public Law 94-142. Except Child 1979;464-6.

16. Hillman, Jr., WA. Special forward. Except Educ Quart 1982;3:viii, ix.

17. Weitzman M. School and Peer Relations, Pediatr Clin North Am 1984;31:59-69.

18. Whitehouse R, Shope JT, Graham-Tomasi R, et al. Educational needs of school personnel working with children with juvenile rheumatoid arthritis. Abstracted. Arthritis Rheum 1983;26(suppl):84.

19. Yoshida RK, Fenton KS, Kaufman MJ, Maxwell JP. Parental involvement in the special education pupil planning process: the school's perspective. Except Child 1978;531-4.

20. Lusthaus CS, Lusthaus EW, Gibbs H. Parents' role in the decision process. Except Child 1981;256-7.

21. Walker DK. Care of chronically ill children in schools. Pediatr Clin North Am 1984;31:221-3.

22. Baird S, Ashcroft S. Need-based educational policy for chronically ill children. In: Hobbs N, Perrin J eds. Issues in the care of children with chronic illness. San Francisco: JosseyBass, $1985 ; 656-71$. 